This is the accepted version of the article:

Bastús N.G., Puntes V.. Nanosafety: Towards safer nanoparticles by design. Current Medicinal Chemistry, (2018). 25. : 4587 - . 10.2174/0929867324666170413124915.

Available at:

https: //dx.doi.org/10.2174/0929867324666170413124915 


\title{
Nanosafety: Towards Safer Nanoparticles by Design
}

\author{
Neus G. Bastús ${ }^{\mathrm{a}}$ and Víctor Puntes $\mathrm{s}^{\mathrm{a}, \mathrm{b}, \mathrm{c}^{*}}$ \\ a Institut Català de Nanociència i Nanotecnologia (ICN2), CSIC and The Barcelona Institute of Science \\ and Technology (BIST), Campus UAB, 08193, Bellaterra, Barcelona, Spain. \\ b Institució Catalana de Recerca i Estudis Avançats (ICREA), P. Lluís Companys 23, 08010 Barcelona, \\ Spain \\ c Vall d'Hebron Institut de Recerca (VHIR), 08035, Barcelona, \\ * To whom correspondence should be addressed: victor.puntes@icn2.cat
}

\begin{abstract}
The continuous development of Nanotechnology is progressively introducing nanoparticles into society. However, little is known about the safety of nanoparticles and functions of engineered nanomaterials, in particular how the physicochemical properties of the materials relate to mechanisms of injury at the nanobio interface. While comprehensive knowledge on the potential toxicity of NPs is still lacking, as time goes by and research in the field continues, different aspects, such as interactions with the immune system, perturbation of cellular membranes, transportation of toxic moieties and others are emerging as potentially hazardous aspects of NPs. As a result, this rapidly advancing new field requires the development of novel test strategies based on the contribution of toxicological pathways to the pathophysiology of disease that allow complex toxicants to be screened in robust, mechanism-based assays in which the bulk of the investigation can be carried out at the cellular and biomolecular level whilst maintaining limited animal use. A review of these strategies will help to provide guidelines for synthetic nanochemists on how to design NPs to be safe during their full life cycle while maintaining their parental desired properties.
\end{abstract}




\section{Introduction}

The rapidly growing field of nanoscience and nanotechnology has given rise to a new form of material, engineered inorganic nanoparticles (NPs), which shows unprecedented potential for revolutionizing many fields of materials science and for transforming established technologies. Due to the small size and high surface area of NPs, these materials have outstanding electrical, optical, magnetic, structural and chemical properties which have been exploited for many new industrial and consumer products.[1-4] Additionally, the fact that inorganic NPs are similar in size to intra- and extracellular biological building units, allows them to specifically interact with molecular and cellular processes and to manipulate biological states, structures and functions in a radical new way, which makes them extremely attractive for biomedical applications.[5-9]

Despite these opportunities, the widespread use of engineered NPs has created growing concerns about their possible adverse effects following intentional and unintentional exposure.[2, 10] Thus, the same physicochemical properties that offer great promise to provide scientific and technological breakthroughs may also lead to unexpected toxicities not anticipated from materials of the same composition in bulk form.[11-13] In this sense, a complete understanding of the size, shape, composition and aggregationdependent interactions of engineered NPs with biological systems is lacking[14], thereby provoking keen interest in nanotoxicology research.[15, 16] The initial strategy was to address NP toxicity as "new chemical substances" and to base safety assessment on established methods for chemical toxicity, including a plethora of in vitro assays for cell toxicity, immunotoxicity, and genotoxicity on humans, rodents and invertebrates. Resulting studies have reported that in some conditions, engineered NPs may induce disparate deleterious biological effects, including membrane permeation, DNA damage, metabolic interference, immune exacerbation, inflammation and induction of oxidative stress.[17-21]

Although frequent attempts have been made to reconcile initial nanotoxicology studies, the toxicity data generated is conflicting and inconsistent, resulting in a lack of sufficient significance to confidently determine the boundaries for safe use of NPs in commercial products.[22] These limitations are mainly related to the diversity of nanomaterials studied, degree of purification, variety of coatings and testing on different cell lines under different cell culture conditions, the particular-complex and elusive- behavior of engineered NPs and the lack of a commonly accepted comprehensive classification system. A number of these studies have focused on traditional toxic nanomaterials presenting a large size distribution, while recently engineered NPs with well-defined sizes have been poorly studied.[23] Moreover, much of this research has concentrated on empirical evaluation of toxicity with less attention being given to the relationships between the physicochemical properties of the material and toxicity thereby limiting information for predicting the toxicity of apparently similar NPs. As a result, there is a pressing need to optimize synthesis techniques to produce monodisperse materials with controlled variations of single parameters (as size, shape or surface state). Moreover, NPs can interfere with several of the well-established 
methods for in vitro toxicity testing[24] and hence the development and use of validated assays is still a critical issue. Finally, despite the increasing body of evidence that pristine NPs can enter and affect organisms when dosed under standard exposure scenarios, this evidence often lacks proper exposure assessment in terms of the study of the changes undergone by NPs during exposure time. In this sense, there is in general a lack of thorough characterization of NPs during their evolution in biological media.

The potential hazards of engineered NPs, acute or chronic, direct or indirect, are not only determined by the physicochemical properties of the engineered NPs per se but also on the interactions of these NPs with immediate surrounding environments. As a result, the aim of promoting the timely and safe development of engineered NPs, cannot be achieved via traditional studies as they address one material at one time.[25] Indeed, engineers produce new materials and products faster than biologists can analyze them, which undoubtedly limits the evaluation of their adverse effects. Consequently, the development of a safer design strategy of engineered NPs requires an understanding of both intrinsic (synthetic) properties together with their extrinsic responses to external stimuli . On the one hand, it must involve the study of how the intrinsic properties, i.e., size, shape, composition and structure of the material, contribute to the potential toxicity of the material in question. On the other hand, it must include investigation of the NP evolution in robust, reallife in vitro and in vivo system models in order to study how these properties are transformed after exposure.

This is an essential point for understanding the critical biological interactions of NPs, since these transformation processes may result in new mechanisms of toxicity[26], including redox activity and generation of reactive oxygen species (ROS)[27, 28], dissolution and yielding of toxic ions[29, 30], and inflammasome activation.[31] Among them, oxidation-induced damage has emerged as a nanotoxicity paradigm[11], promoting the activation of biochemical cascade reactions that can ultimately result in cell damage (depletion of reduced glutathione, lipid peroxidation and DNA damage) and even cell death.[32, 33] In addition, metal ions released from NPs have also been found to cause cell damage, normally as the direct consequence of the dissolution of the NPs.[34] Although all these toxicity mechanisms have been found to be closely related to the unique physicochemical properties of the NPs (size, shape and composition), a satisfactory framework to univocally correlate and anticipate predictive paradigms for nanotoxicity has not yet been developed. To this end, new systematic approaches are needed, with the aim of determining whether and how the analysis of in vitro and in vivo responses may be used to understand the different mechanisms of toxicity and their dependence on the morphological and physicochemical properties of engineered inorganic NPs, and whether and how their analysis can be used to develop predictive toxicological models.

Nanosafety aims for a solution through the safer design (and re-design) of nanostructured materials, optimizing both performance and safety, by resolving which structural features lead to the desired properties and modifying them to avoid their detrimental effects without losing their desired nanoscale properties in the process. This solution needs to be considered by taking a comprehensive definition of safety, as avoiding detrimental effects based on acute, chronic or repeated exposure/uptake/retention of NPs 
under realistic/controlled exposure conditions and considering both healthy and compromised hosts and ecosystems. Moreover, starting with known toxic NPs, the final aim should be the re-design of such detrimental specific NP characteristics and to redefine the way they should be manipulated from the beginning to the end ot their life cycle. Consequently, known NPs could be used in a safe manner and new manufactured ones may be easily evaluated. The idea is to develop the "safety by design" paradigm into a practically feasible "safety by redesign" paradigm, which can be implemented for products in the marketplace.

In this context, the focus of this review is to provide an overview of the state-of-the-art of this topic, discussing the main strategies and particular aspects to be considered for a predictive "safe by design" safety assessment of engineered inorganic NPs. Furthermore, we also provide a brief description of the studied structures, their interactions with cells in in vitro cell culture systems, and their potential molecular effects (e.g. inflammation), aiming to define the link between these studies and their toxicological effects.

\section{Towards a Systemic Approach for Assessing Nanosafety of Engineered Nanoparticles}

For the systematic assessment of the potential toxicity of engineered NPs, a multidisciplinary predictive approach plan is required, based on a fluid and strong cross-interaction between the different fields involved allowing the comparison of results of different studies and ultimately providing guidlines for the re-design of safer NPs. Figure 1 illustrates the multidisciplinary approach, which involves four different tasks: i) a systematic plan for NP production, analysis and classification, ii) the study of their evolution in the physicochemical and biological environments to which they are exposed; iii) the study of their biological effects and complex biological responses in healthy and compromised states; and iv) the understanding of their fate, transformation and effects in relevant environmental scenarios.

For the identification of the critical physicochemical properties of the NPs that confer the ability to induce an adverse effect in biological systems, data on a wide range of NP models representative of the most common ones along with their possible variations is required. This involves the development of widely available systematic libraries of NPs to enable both the generation of sufficient datasets for development and validation of models and the identification of the physicochemical properties that are involved in the different mechanisms of toxicity of these materials. $[35,36]$ Preliminary data in the literature indicate that commonalities of the effects produced by NPs on biomolecules and biological systems allow the classification and grouping of a large number of NPs into a few representative families based on composition, morphology, functionality, physicochemical state and biological behavior.[37-41] In this regard, the use of data repositories for data analysis, data transformation, machine learning and modelling is needed to stablish quantitative structure-activity relationship (QSARs) enabling the prediction of NP toxicity and toxicity mechanisms.[42-44]

Furthermore, it is also important to investigate not only the biological response from cells and organisms exposed to them but also the fate of engineered NPs themselves as they are exposed to biological and 
ecological environments.[45] Traditionally, NPs have often been treated as stable objects. However, NP evolution is now being accepted, as for example in the case of identification of formation and dynamics of the protein corona when exposed to biological fluids, aggregability of NP (previously observed but largely ignored) and dissolution which are being acknowledged as critical when assaying NP safety.[46]

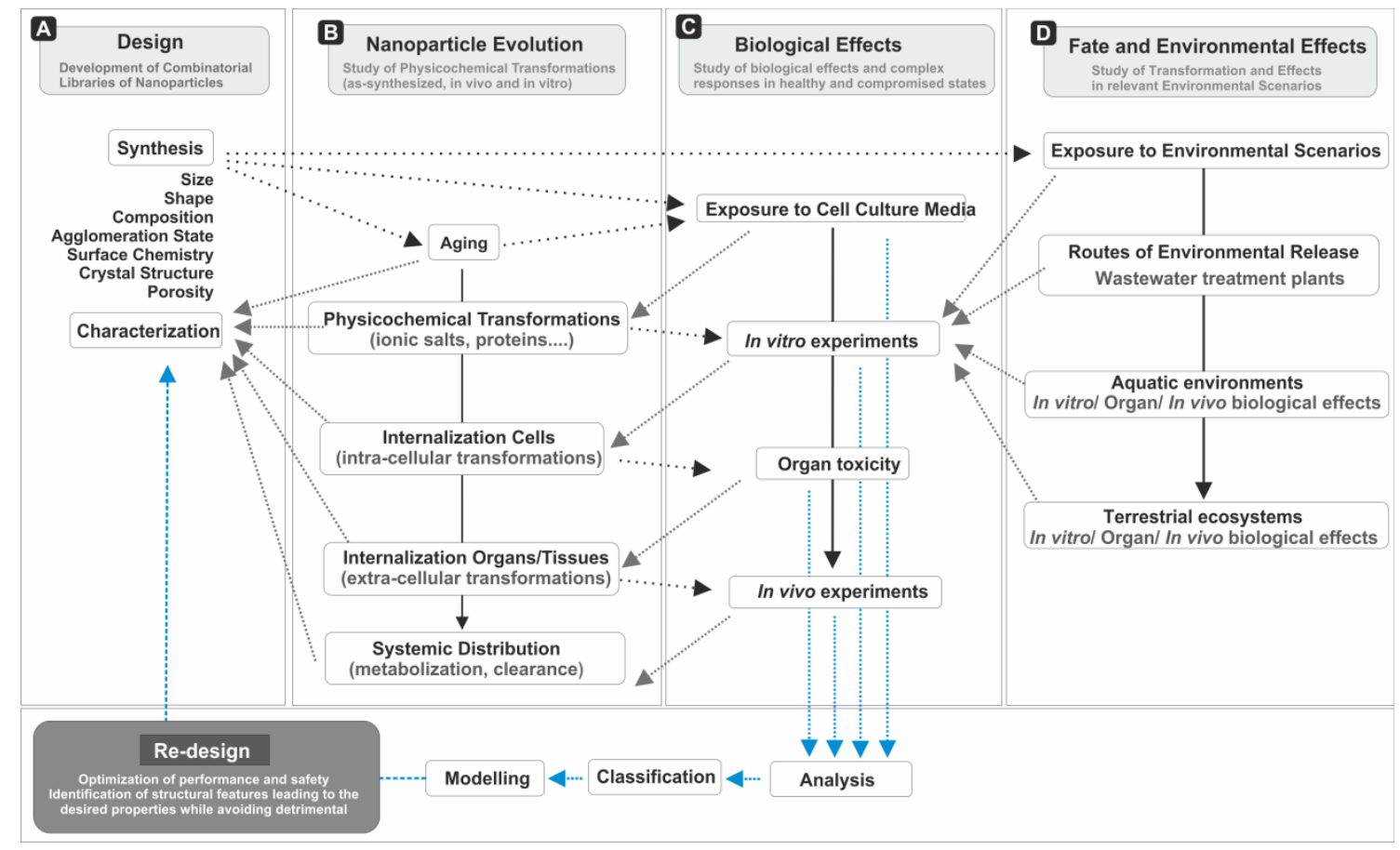

Figure 1. Schematics of the synergy between fundamental concepts. The multidisciplinary systemic approach to assess nanosafety of engineered NPs involves four different tasks: i) a systematic plan for NP production, analysis and classification $(\boldsymbol{A})$, ii) the study of their evolution in the physicochemical and biological environments to which they are exposed (B); iii) the study of their biological effects and complex biological responses in healthy and compromised states $(\boldsymbol{C})$; and $i v)$ the understanding of their fate, transformation and effects in relevant environmental scenarios $(\boldsymbol{D})$.

The following section includes a summary of the current efforts to develop a systematic plan for NP production, analysis, and study of their evolution in the physicochemical and biological environments to which they are exposed together with the reported strategies for study of their biological effects and complex biological responses. A description of the current in vitro and in vivo analysis techniques will also be discussed within the context of the ongoing challenges and recommendations made for achieving more reliable measures for nanomaterial safety. 


\section{Development of combinatorial libraries of NPs}

To date, only a few NPs have undergone safety studies while many others have never been tested, or not tested in particular formats that would allow comparing their effects. Therefore, for a predictive toxicological approach, a description of sufficient variation in materials and properties is needed. Indeed, comprehensive knowledge of nanomaterial not only from composition and morphology but also from a chemical and physical perspective is critical, since physicochemical properties are strongly coupled to their composition and morphology. For this purpose, the development of combinatorial libraries including systemic variation and accentuation of physicochemical properties is highly desirable not only to provide a robust platform to study the correlations between materials properties and toxicity but also to incorporate and renormalize the material data from different sources for hypothesis validation and development of toxicity models.[47] Significantly, an important challenge is the minimization of variability in manufacturing methods[48], the development of robust and reproducible synthesis strategies[49, 50], and the reaction scaling necessary to produce adequate volumes of uniform NPs.[51]

Through the control of NP synthesis, it is possible to derive thousands of variations by changing composition, size, shape, surface chemistry (charge and functional group), and crystal structure, aging state and other factors, as the model shows in Figure 2. Among the parameter variables, size is especially interesting since it is with the smaller size range (from a few to $100 \mathrm{~nm}$ ) where most novel phenomena occur due to surface, quantum confinement and finite-size effects. Indeed, the size dimension of NPs has been found to be a critical parameter in determining the behavior and fate of NPs in biological systems. [52, 53] Although some studies claim that the nanoparticle-mediated cellular response is size-dependent[54, 55], others disagree that it plays such a critical role.[56] These inconsistences result from the limited number of samples tested in each particular study, covering a limited size range, and/or the particular cellular response studied.[55] Moreover, other properties such as morphology and crystal structure need to be carefully evaluated and kept invariable when the size effects are studied. This is particularly important in those NPs known to be highly sensible to morphology and crystal phase transformation as the size changes since the specific arrangement of atoms has been found to be closely relevant to their potential oxidative reactivity.[57] As a result, it has been shown that NPs present a different reactivity with respect to various crystal morphologies and structures which ultimately affects total cell uptake and toxicity.[58] A wellknown example is $\mathrm{TiO}_{2}$ in which both rutile and anatase crystal structures exhibit the same chemical composition but a different crystalline structure, being proved that the levels of toxicity and the mechanism of cell death depend on this crystalline structure.[59] Other than primary size, NPs also serve as a model for many solid state nanomaterials (especially metals and metal oxides) whose nanostructured surface or

body may be considered as an aggregate (ordered or not) of NP-like units. In these systems, the aggregation state of NPs (concentration rather than size) has been found to play a critical role in their toxicity.[60, 61] 


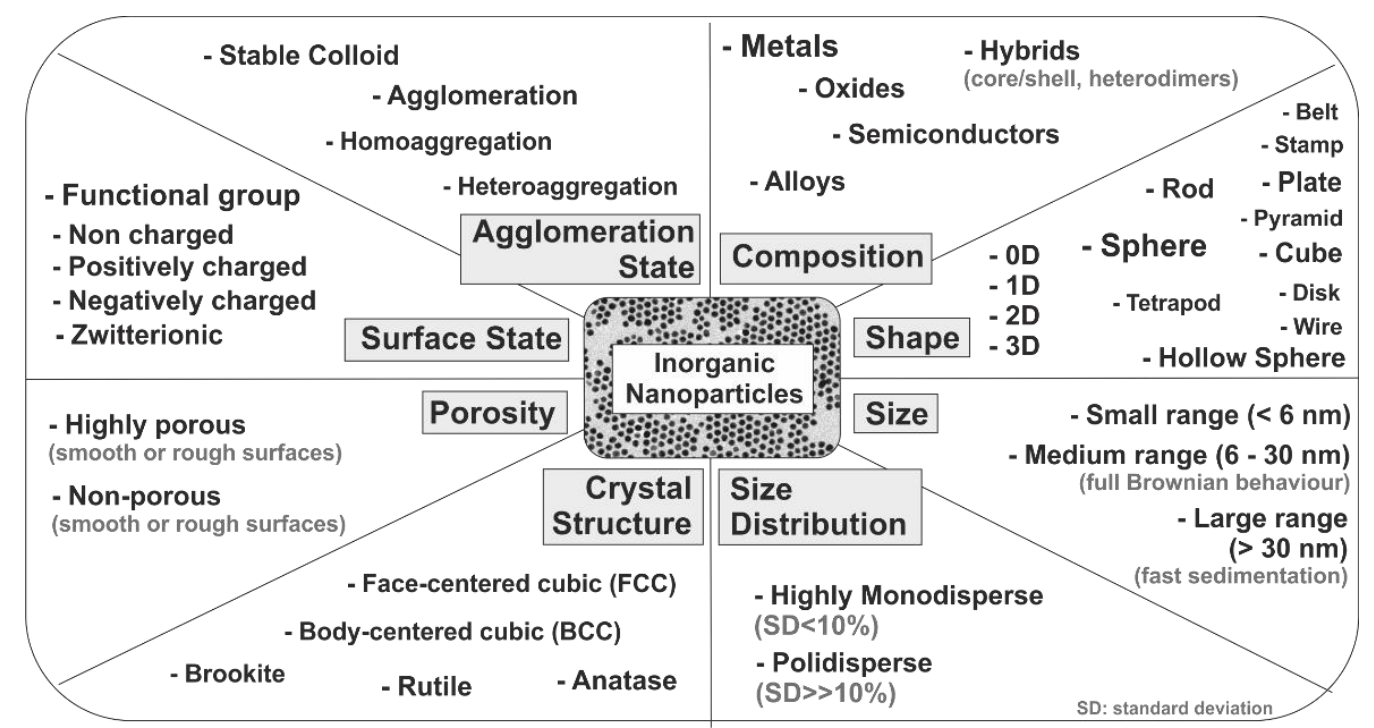

Figure 2. Development of combinatorial libraries of NPs. Combinatorial libraries of engineered inorganic NPs can be built through the control of NP synthesis varing the major physicochemical properties involved in toxicity. Property variations include nanoparticle size, shape, composition, porosity, crystal structure, surface state, agglomeration statea and size distribution. A single property variation may also change other properties which has to be carefully evaluated.

The particular characteristics of NP surface chemistry has been found to be another critical parameter altering the behavior and fate of NPs in biological systems which can be controlled during their synthesis.[62, 63] Since NPs can be produced with different functional groups on their surface, by modifications of NP's surface coating, charge and hydrophobicity their reactivity may be modified, improving the stability of the colloidal sample and ultimately altering their interactions with the (biological or ecological) surrounding, ultimately increasing or decreasing their toxicity towards cellular or biological organisms.[30] It is worth mentioning that when NP charge is altered, often, the $\mathrm{pH}$ or the chemical nature of the ion/molecule that bears these charges also changes, illustrating how at this scale, charge and surface state are strongly coupled. The same argument can be applied to shape control since, commonly, different shapes are obtained because of the choice of different surfactants. In this sense, when preparing the NP, it is important to understand that a change in size and shape often leads to a change in surface state and vice versa.

\section{Physicochemical transformations of NPs in physiological environments.}

Since the properties of engineered NPs are strongly determined by both intrinsic (synthetic) and extrinsic (environmental) aspects, the study of the physicochemical transformations of engineered NPs in the particular context in which they are immersed represents a cornerstone in the development of a knowledge base on predictive and actual nanosafety. Due to their higher percentage of surface atoms and their colloidal nature, NPs experience processes that transform them towards more stable thermodynamic states[18, 64], including aggregation, corrosion, dissolution and interaction with media proteins, which determine the 
nature of the nano-bio interface (Figure 3). [64-70] From the NP point of view, these interactions can cause phase transformations, particle aggregation, reconstructuring and dissolution. All of these processes have a significant influence on the reactivity, bioavailability and pharmacokinetics of NPs[71], affecting their persistence and ultimately leading to toxic effects.[66, 72-74] For example, extracellular agglomeration of NPs, or the agglomeration occurring prior to or during exposure to in vitro or in vivo toxicity testing, has a significant impact on the observed toxicological effects and conclusions about their size-dependent toxicity.[60, 75] In this regard, one interesting trend found was that with most NPs tested, the addition of serum to the cell culture media helped to mitigate the tendency and effects of NP agglomeration.[76, 77] From the biomolecules point of view, these interactions may lead to the opsonization, formation of Protein Coronas (PCs) of a different nature[77-80] (the so-called soft and hard corona), denaturation of proteins,[81] and the formation of NP-protein complexes,[79] which inevitably provide them with a new biological identity,[82, 83] eventually promoting the activation of signaling pathways[84-86] and ultimately determining their physiological response and toxicity.[87, 88] The impact of the protein corona on cytotoxicity, and immunotoxicity has been widely studied. We refer the reader to a number of excellent reviews on each of these topics.[30, 87-91]

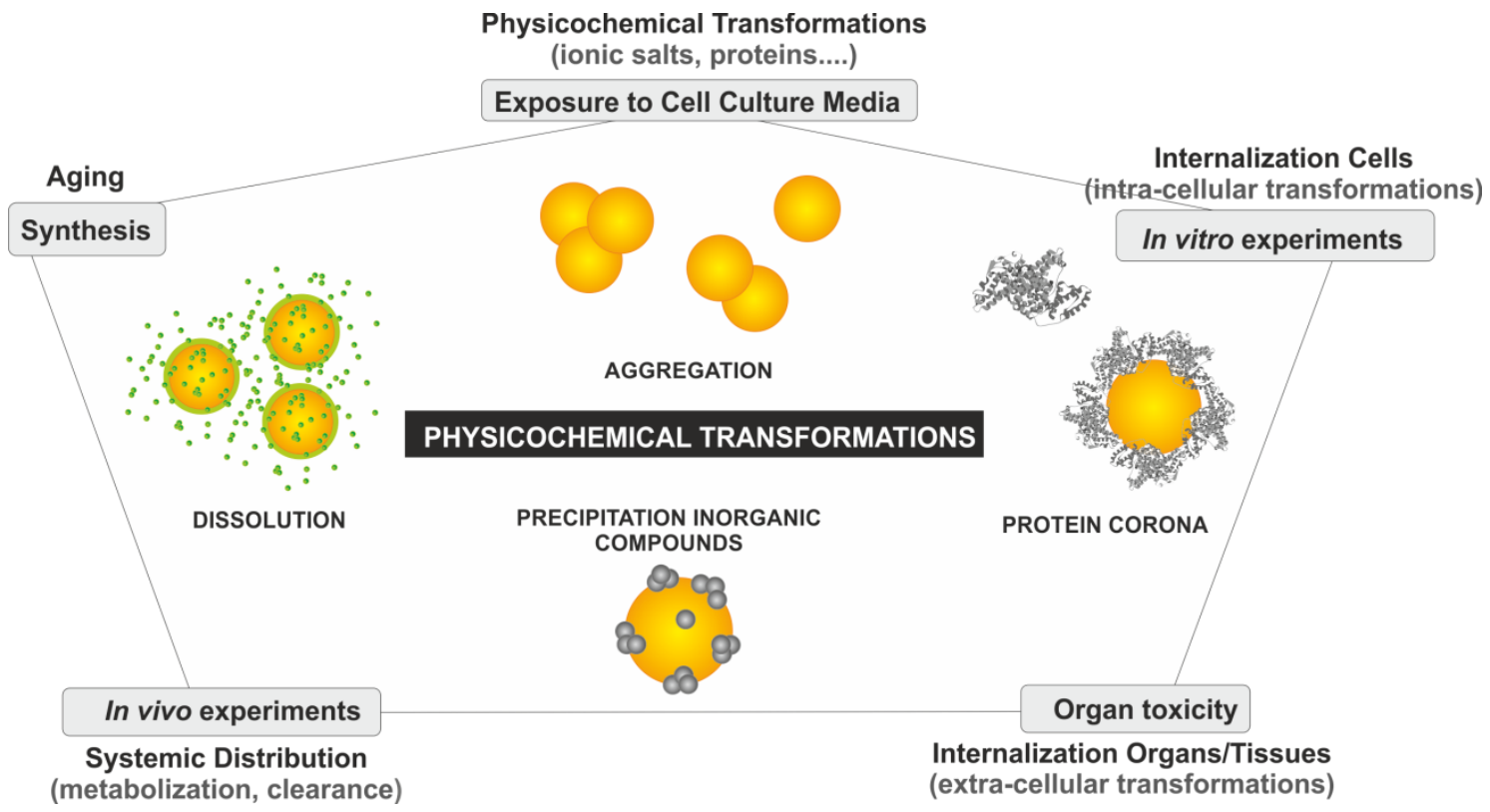

Figure 3. Examples of physicochemical transformations of the properties of engineered inorganic nanoparticles immediately after their synthesis (aging) and/or after their exposure to biological/ecological environments. To elucidate the mechanisms of biological action of NPs, physicochemical transformations, including dissolution, oxidation, homoaggregation and heteroaggregation (interaction with proteins) must be carefully considered and comprehensive characterizated at each stage of the in vitro and in vivo testing. 
Due to the evolution described above, the evaluation of the properties of as-synthesized materials does not actually represent the properties of the materials during or following their biological or ecological exposure. Consequently, a comprehensive characterization of NP properties during their full life cycle is needed in order to determine their contribution to toxicity.[92, 93] Intense efforts have been devoted to understanding the particular time-dependent evolution of as-synthetized NPs in the immediate surrounding environment.[70] Some of them have addressed this point by a combination of analytical techniques[72, $84,94]$ and/or analyzing the atomic and electronic structure of NPs coupled to coordination chemistry studies.[95, 96] These analyses has given insight into the electrochemical properties of the NP core in relation to the production of ROS.[97] Other approximations have included modelling studies of NP surface interactions with other NPs and proteins, with the aim of understanding the formation process of the PCs or NP aggregates.[98] In all cases, these analyses have to be designed to incorporate and compare the available data for rationalization. Undoubtedly, the development of systematic exposure protocols and reliable methods for assessing NP internalization and their kinetics in living organisms may allow a full description of the exact nature of NP toxicity in the near future.

\section{Evaluation of the Biological Impact of Engineered Inorganic Nanoparticles}

Addressing how the adverse effects of engineered NPs translate and progress up the layers of biological complexity, covering molecular to cellular, organ to organism and individual to ecological levels is of crucial importance to determine the final impact of NPs. In this respect, biological evaluation has to cover all of these stages, from molecular pathways, cell biology and advanced in vitro systems up to in vivo models, from a particular point-of-entry to multi-exposure scenarios (Figure 4). Among them, of special relevance is the large size of NPs compared to small molecules and the effects that they may have on permeability and barrier interaction of NPs in biological tissues, since ultimately, NPs need to cross barriers, like the cell membrane, skin and mucosal barriers, to fully express their biological impact.

\subsection{The Effect of Nanoparticle on Cellular Behavior}

Cell functions depend on assembly forces.[70] Therefore, besides obvious toxicity[99, 100], more subtle effects of NPs on cells may have important implications for their impact on biological systems. In this sense, a systemic approach for assessing nanosafety of engineered NPs should include the study and analysis of the broad spectrum of different NP-cell interactions[70, 101] and their impacts on much different cellular physiology function levels (such as mitochondria, ROS production, cytoskeletal, intracellular calcium, and membrane currents).[102]

There are indications that the direct toxicity of NPs can be related to their ability to interfere with the normal functioning of the plasma membrane.[103-105] In this regard, biomembrane models have been widely used for the study of NP-cell interactions and how this affects the self-assembly and organization of their structure (Figure 5). Interesting examples include the study of the interactions between the NP and model phospholipidic bilayer membranes[106, 107], particularly the cellular adsorption, uptake, intracellular 
trafficking and exit of $\operatorname{NPs}[19,108]$, further extended to cellular systems.[19, 108] Although some of them were designed to systematically evaluate the specific NP properties which influence their interaction with the cell membrane, especially after their unintended (protein corona) or intended (functionalization) coating $[13,37,109,110]$, at present, there is a dearth of understanding of the particular correlation of the biological response with the physicochemical properties of the NPs involved.[37] Moreover, further evidence on whether and how these properties may or may not be stressful for the cells ("latent toxicity") are still poorly understood.[109] This lack of understanding is in part due to complex behavior of engineered NPs in biological systems and the fact that mechanisms that govern cell internalization of NPs are also dependent on the cell type[109, 111] Indeed, the fate of NPs within cells often involves processes of aggregation and dissolution, and protein coating, limiting the significance of obtained results.[70] In this sense, the characterization of the reactivity of the NPs before and after internalization is also critical for understanding their cellular uptake and intracellular trafficking.[109]
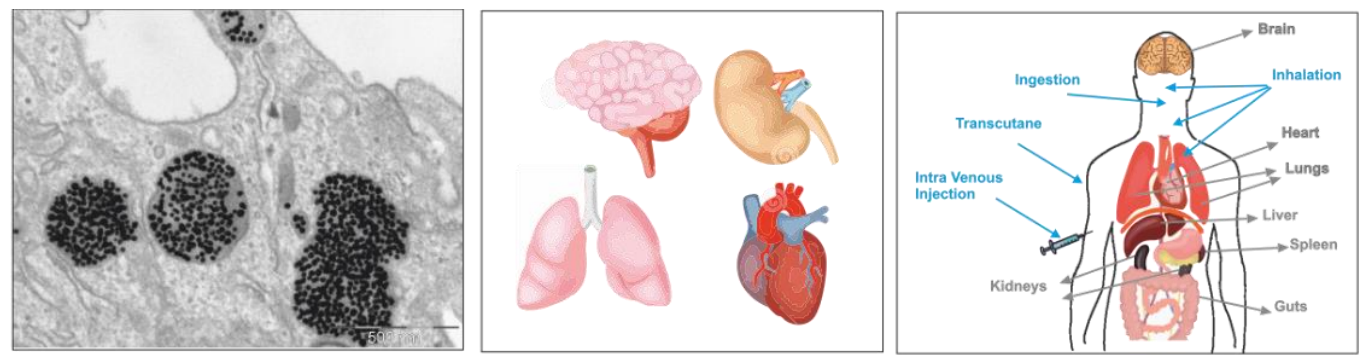

\section{In vitro toxicity}

Cellular toxicity

Interactions with membranes DNA damage

\section{Organ toxicity}

Distribution

Pharmacokinetics

Clearence

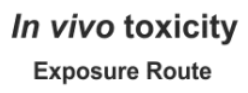

Figure 4. Evaluation of the Biological Impact of Engineered Inorganic Nanoparticles from molecular pathways, cell biology and advanced in vitro systems up to in vivo models, from a particular point-of-entry to multi-exposure scenarios is of crucial importance to determine the final impact of NPs.

In parallel, the response of the cell in the presence of NPs has been also widely studied. Cellular homeostasis is maintained by a complex network of signaling molecules. Therefore, graver disturbances leading to the induction of defense programs are important aspects to study. In this sense, if it is known which receptors or pathways are affected in response to defined properties of NPs, it may be possible to modify the NP accordingly to avoid recognition or to induce tolerogenic signals. Since the immune system is responsible for categorizing external invasions and organizing defenses, it is especially suited for these studies. Intensive efforts have been devoted to clarifying which of numerous possible mechanisms for the induction of cell stress, inflammation and apoptosis are specific for a particular type of NP.[112] This has been assessed by investigating changes in gene expression[113] which have provided important information about the upstream signaling mechanisms involved and gene expression tracked over time that were 
associated with the time-dependent fate of NP within the cell. Concentrations of selected metabolites have been found to be affected by the presence of NP by direct means (adsorption), or indirectly, like protein concentrations by changes in transcription.[114] Metabolites reflecting immunity, cell stress and apoptosis are also interesting parameters studied.[115] Similarly, the study of interactions between NPs and DNA, and further quantification of DNA damage and DNA repair activities in response to NP exposure were also the subject of interesting studies.[116] The reactivity of NPs of various compositions and coatings were studied with isolated DNA and in cells identifying and classifying selected NPs according to their DNA damaging, and oncogenic potential, by direct damage to DNA or by inducing chronic inflammation.[117] These experiments, using a large number of NPs and a variety of cells and endpoints gathered together and analyzed, have allowed determining minimum parameters to set a screening platform for NP-cell interaction.[118]

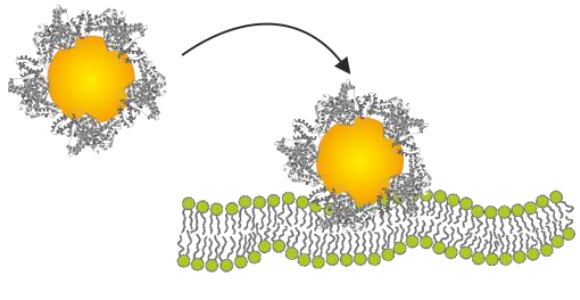

Membrane Attachment (adhesion)

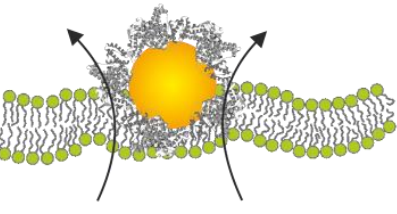

Membrane disruption and leakage

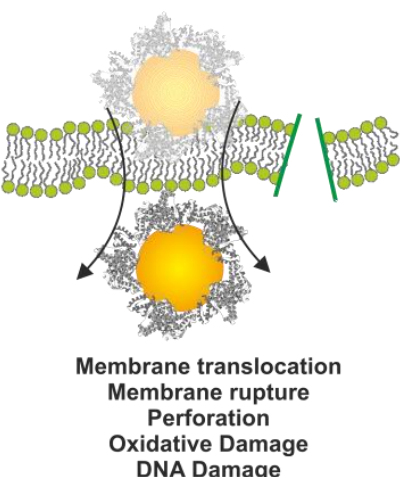

Figure 5. Interactions of Nanoparticles with Cell Membranes. Direct toxicity of engineered NP can be related to their ability to interfere with the normal functioning of the cell membrane. After exposition of inorganic NPs to biological scenarios, NPs may interact with and cross biological membranes leading to membrane disruption, leakage, rupture and perforation. The study and understanding of these processes are key mechanism in determining their effects on biological cells.

When assessing NP-cell interactions, another aspect to consider is the testing of the effects of NPs functionalized with toxins and contaminants that may be realistically present during synthesis (e.g. lipopolysaccharide (LPS)) or of very different origins (e.g. airborne seasonal allergens), in order to study long-term effects of contamination, in particular when assessing nanoimmuno interactions.[20, 119] For in vivo studies (where long-term exposures are assessed), sterilization of the NP represents a greater challenge since autoclaving may cause massive aggregation and chemical methods may alter the NP surface and induce unwanted effects such as corrosion in metals and even toxicity. UV light, another commonly used technique for surface sterilization in biological hoods, may alter NP surface and structural properties. 


\subsection{The Effect of Nanoparticle on Biological Systems}

NPs may enter the human body via various routes, including respiratory pathways, digestive tract, skin contact, intravenous injection, and implantation.[120] After absorption from inhalation, oral, or cutaneous routes, NPs might translocate in the systemic circulation being delivered to various organs and tissues, including liver, spleen, kidneys, heart and brain by the bloodstream and the lymphatic system.[52, 99, 121] Although some ingested or absorbed NPs are metabolized and excreted, others remain accumulated in the body for a long time.[99] The determination of absorption, distribution, metabolism and excretion (ADME) rates of nanoparticles is essential for evaluating potential toxic effects.[122] The route of administration greatly determines the accumulation and elimination of NPs. If the particle is injected orally, they mainly accumulate in intestinal organs (e.g., liver and spleen) and are further eliminated through feces, whereas after parenteral or intravenous administration, they are mostly eliminated via the kidney while traveling through the blood. Moreover, the drainage of NPs through different organs also depends on the physicochemical properties of the NPs. Thus, if the NPs are $<20 \mathrm{~nm}$, they can easily be cleared up by the normal drainage organs, such as the kidney $(<5 \mathrm{~nm})$ or the liver $(10-20 \mathrm{~nm})$ while larger particles $(<200$ $\mathrm{nm}$ ) are eliminated by the reticulo-endothelial system (RES), being eventually accumulated in the spleen, bone marrow, and other RES which may cause systemic toxicity.[123, 124] Although the lungs is not a conventional eliminatory system, it can help in filtering aerosolic NPs with sizes $>100 \mathrm{~nm}$. In this case, alveolar macrophages and mucociliary transporters are the main mode of excretion.[121] This macrophagemediated clearance is size, and surface property selective.[125] A small numbers of NPs can also enter organs that are protected by dedicated barriers, such as the brain[126, 127] and the testis.[128] It is not only size and aggregation state that matters in the excretion and clearance, but also surface properties.[121, 129] Thus, polyethylene glycol (PEG) coating reduces the connection with plasma proteins and results prolonged circulation time, which decreases the immediate accumulation.[130] Readers can refer to some recent review papers summarizing the relationship between NP's physicochemical properties and their in vivo behaviors and fate.[45, 121, 131]

As evidence, it is emerging that the route of entry, and the particular physicochemical properties of NPs (composition, size, shape, surface properties and aggregation state) play a distinct role in determining the organ biodistribution of NPs, and further, that complete understanding of the NP bioresponses is too complex to be fully framed in standard 2D mono-type cell culture models. Therefore, for the development of a predictive "safe by design" approach for engineered inorganic NPs, new biological models to assess risk and determine safety practices are needed. This includes the establishment of 3D co-culture models of primary cells, either based on tissue or on induced pluripotent stem (iPS) cells[132], to study complex responses, and compare health vs. compromised states. Although, a considerable number of the toxicological studies conducted to date have been performed using transformed cell lines, primary cell cultures are closer to the in vivo situation and show greater variability reflecting the reality of biological systems.[133] In this sense, stem cells have been reported as interesting alternatives allowing capture of the genetic complexity 
of the donors, including disease states, and the ability to be differentiated into many cell types. As previously mentioned, the implementation of high-content and high-throughput screening (HCS and HTS) approaches to compare batches of materials, ranging from a few (10-20) to many (100-200) in each comparative analysis, has been of crucial importance in order to compare a wide material range and test multiple concentrations of each batch of NP material to cover a wide dose range.[17, 118] Among the different HTS approaches, interaction with zebrafish embryos/larvae and complement activation in different biological fluids have been especially interesting for initial assessment of NPs in complex biological models.[134, 135] The zebrafish test has become a widely used model for toxicology studies, largely reflecting early development of human and other vertebrates that allow large-scale testing of NPs.[136] More complex in vitro advanced models, including multicellular models of respiratory and gut mucosa, skin, liver, kidney, heart, brain, and blood have been developed, suitable for evaluating the overall mechanisms of interaction with selected NPs.[100, 137] Importantly, each model has to be evaluated in physiological conditions and upon challenge, to reproduce the behavior in healthy $v s$. diseased conditions.

Remarkably, most in vivo and in vitro models currently available for assessing hazard, exposure and consequent risk are based on healthy organisms/conditions. However, this is a widely unrealistic assumption since during the course of disease, the body barriers may be altered, the biochemistry modified, the redox state of the tissue changed (e.g.: hyperoxia during inflammation and hypoxia in solid tumors), and the cell defense mechanisms weakened. All of these situations may make NPs that were non toxic in healthy conditions become so. In this regard, the analysis of subtle -but critical- effects, which escape the screening performed in simple models, and the study of prolonged exposure studies (including accumulation, repeated doses and memory) which actually disrupt normal activity and lead to posterior malfunctioning and diseases, have been found of crucial importance for a systemic and robust approach for assessing the nanosafety of engineered NPs.[25]

For events that cannot be modelled in vitro with human cells - developmental, ADME (absorption, distribution, metabolism, and excretion), validation of disease conditions - relevant in vivo animal models have also been used. A few recent studies have focused on in vivo biodistribution of engineered NPs as it relates to their physicochemical properties.[45] Although in these studies the location of NPs at different time points and at different doses were quantitatively mapped, thus far, no general conclusion has been reached as to how size, shape, aggregation and surface chemistry affect NP bio-distribution.[99]

\section{Nanoparticles and Environment}

The increase in the production and use of engineered NPs has made exposure of these compounds to the natural environment more and more likely. As a result, the evaluation of the environmental risk of engineered NPs has been included in the systematic evalatuion of their safety assessment.[138, 139] NPs can be released into the environment, either directly through their use, for instance in soil remediation or as pesticide modulators, or indirectly as waste after use in personal care products or unintentional spills or 
accidents.[140] Within their life cycle, the environmental release of NPs is of importance for two main reasons. First, because NPs may interact with soil, sediment, water, air or any other environmental constituent, potentially transforming their properties and behavior beyond those previously considered. Second, because NPs interact with organisms and may accumulate within them and affect their functioning. Mechanisms between NPs and biological entities occurring inside a living body are analogous and complementary to what happens in the environment. In this sense, the exploration of how NP design features (structure, surface, coating etc.) help to govern the entry, passage and fate (reactions and ageing) of NPs in the environment and organisms have been an important focus of attention.

Charting what happens to NPs released in various reactive parts of the environment and linking this to effects across species of increasing complexity, has been reported as key to understanding what NP properties control how NPs enter organisms, distribute, accumulate, transform and cause effects. A major route of environmental release of NPs is considered to be domestic and industrial wastewater. Several studies have addressed the study of the fate, transformation and effects of NPs in wastewater treatment plants (the environmental gatekeeper for NPs used in consumer products), where NP fate and transformation was tracked after their exposure to this highly reactive environment.[141-143] Similarly, the behavior of NPs has been studied in fresh and marine aquatic environments of greatly varying chemistry, and the effect studies included potentially exposed organisms covering all possible uptake routes (e.g. biofilms, filter \& sediment feeders/dwellers) and predators (bacteria, algae, Daphnia, insect larvae, mud shrimps, mussels and fish).[144-146] Studies were extended to small-scale terrestrial ecosystems, mimicking environmental conditions, allowing long-term (years) and realistic low dose exposures of several species (microbes, crop plants, invertebrates with different living and feeding habits, and guilds) simultaneously, as well as evaluation of soil function and leachate collection in time (route to groundwater).[138, 144]

\section{Conclusions and Outlook}

The rapidly advancing field of nanoscience and nanotechnology is univocally associated with growing concerns about their possible adverse effects following intentional and unintentional exposure. In this regard, a system for the systematic assessment of the potential toxicity of engineered NPs is required. Such a system needs to be based on a multidisciplinary predictive approach plan with a fluid and strong crossinteraction between the different fields involved. In this review, we have summarized recent developments of novel nanosafety strategies addressing the "safe-by-design" paradigm for optimizing both performance and safety, allowing the comparison of results of different studies and ultimately providing guidelines for the re-design of safer NPs. We have identifiyed four different tasks involved, including a systematic plan for NP production, analysis and classification, the study of their evolution in the physicochemical and biological environments, the study of their biological effects and complex biological responses in healthy 
and compromised states, and an understanding of their fate, transformation and effects in relevant environmental scenarios. The resulting discussion is intedend to provide guidelines for synthetic nanochemists on how to design NPs to be safe during their full life cycle while maintaining their parental desired properties.

\section{Acknowledgments}

We would like to thank Diana Boraschi, Albert Duschl, Claus Svendsen, Wolfgang Parak and many others who have helped us in this detailed overview of the state of the art of nanosafety. We acknowledge financial support from the Spanish Ministerio de Ciencia e Innovación (MICINN) (MAT2015-70725-R) and from the Catalan Agència de Gestió d'Ajuts Universitaris i de Recerca (AGAUR) (2014-SGR-612). Financial support from the FutureNanoNeeds (FP7-NMP-2013-LARGE-7) Projects financed by the European Community under the FP7 Capacities Programme is gratefully acknowledged. N.G.B. acknowledges financial support by MINECO through the Ramon y Cajal program (RYC-2012- 10991) and by the European Commission Seventh Framework Programme (FP7) through the Marie Curie Career Integration Grant (322153-MINE). 


\section{References}

[1] Aitken, R.J.; Chaudhry, M.Q.; Boxall, A.B.A.; Hull, M., Manufacture and use of nanomaterials: current status in the UK and global trends. Occupational Medicine, 2006, 56, (5), 300-306.

[2] Maynard, A.D.; Aitken, R.J.; Butz, T.; Colvin, V.; Donaldson, K.; Oberdorster, G.; Philbert, M.A.; Ryan, J.; Seaton, A.; Stone, V.; Tinkle, S.S.; Tran, L.; Walker, N.J.; Warheit, D.B., Safe handling of nanotechnology. Nature, 2006, 444, (7117), 267-269.

[3] Schmid, K.; Riediker, M., Use of Nanoparticles in Swiss Industry: A Targeted Survey. Environmental Science \& Technology, 2008, 42, (7), 2253-2260.

[4] Maynard, A.; Michelson, E., 2006.

[5] Moghimi, S.M.; Hunter, A.C.; Murray, J.C., Nanomedicine: Current status and future prospects. FASEB J., 2005, 19, (3), 311-330.

[6] Riehemann, K.; Schneider, S.W.; Luger, T.A.; Godin, B.; Ferrari, M.; Fuchs, H., Nanomedicine Challenge and perspectives. Angewandte Chemie - International Edition, 2009, 48, (5), 872-897.

[7] Dreaden, E.C.; Alkilany, A.M.; Huang, X.; Murphy, C.J.; El-Sayed, M.A., The golden age: gold nanoparticles for biomedicine. Chem. Soc. Rev., 2012, 41, (7), 2740-2779.

[8] Jans, H.; Huo, Q., Gold nanoparticle-enabled biological and chemical detection and analysis. Chem. Soc. Rev., 2012, 41, (7), 2849-2866.

[9] Schütz, C.A.; Juillerat-Jeanneret, L.; Mueller, H.; Lynch, I.; Riediker, M., Therapeutic nanoparticles in clinics and under clinical evaluation. Nanomedicine, 2013, 8, (3), 449-467.

[10] Dowling, A.; Clift, R.; Grobert, N.; Hutton, D.; Oliver, R.; O’neill, O.; Pethica, J.; Pidgeon, N.; Porritt, J.; Ryan, J., Nanoscience and nanotechnologies: opportunities and uncertainties. London: The Royal Society \& The Royal Academy of Engineering Report, 2004, 61, e64.

[11] Nel, A.; Xia, T.; Mädler, L.; Li, N., Toxic Potential of Materials at the Nanolevel. Science, 2006, $311,(5761), 622-627$.

[12] Fadeel, B.; Garcia-Bennett, A.E., Better safe than sorry: understanding the toxicological properties of inorganic nanoparticles manufactured for biomedical applications. Advanced drug delivery reviews, 2010, 62, (3), 362-374.

[13] Krpetić, Ž.; Saleemi, S.; Prior, I.A.; Sée, V.; Qureshi, R.; Brust, M., Negotiation of Intracellular Membrane Barriers by TAT-Modified Gold Nanoparticles. ACS Nano, 2011, 5, (6), 5195-5201.

[14] Colvin, V.L., The potential environmental impact of engineered nanomaterials. Nat Biotech, 2003, $21,(10), 1166-1170$.

[15] Oberdörster, G.; Oberdörster, E.; Oberdörster, J., Nanotoxicology: An Emerging Discipline Evolving from Studies of Ultrafine Particles. Environ. Health Perspect., 2005, 113, (7), 823-839.

[16] Oberdörster, G.; Stone, V.; Donaldson, K., Toxicology of nanoparticles: A historical perspective. Nanotoxicology, 2007, $1,(1), 2-25$. 
[17] Nel, A.; Xia, T.; Meng, H.; Wang, X.; Lin, S.; Ji, Z.; Zhang, H., Nanomaterial toxicity testing in the 21st century: use of a predictive toxicological approach and high-throughput screening. Acc. Chem. Res., 2012, 46, (3), 607-621.

[18] Casals, E.; Gonzalez, E.; Puntes, V.F., Reactivity of inorganic nanoparticles in biological environments: insights into nanotoxicity mechanisms. Journal of Physics D-Applied Physics, 2012, 45, (44), 443001.

[19] Zhao, F.; Zhao, Y.; Liu, Y.; Chang, X.; Chen, C.; Zhao, Y., Cellular uptake, intracellular trafficking, and cytotoxicity of nanomaterials. Small, 2011, 7, (10), 1322-1337.

[20] Dobrovolskaia, M.A.; Germolec, D.R.; Weaver, J.L., Evaluation of nanoparticle immunotoxicity. Nature Nanotechnology, 2009, 4, (7), 411-414.

[21] Fischer, H.C.; Chan, W.C.W., Nanotoxicity: the growing need for in vivo study. Curr. Opin. Biotechnol., 2007, 18, (6), 565-571.

[22] Krug, H.F., Nanosafety Research-Are We on the Right Track? Angewandte Chemie International Edition, 2014, 53, (46), 12304-12319.

[23] Oberdorster, G.; Oberdorster, E.; Oberdorster, J., Nanotoxicology: an emerging discipline evolving from studies of ultrafine particles. Environ Health Perspect, 2005, 113, (7), 823-839.

[24] Wörle-Knirsch, J.M.; Pulskamp, K.; Krug, H.F., Oops they did it again! Carbon nanotubes hoax scientists in viability assays. Nano Lett., 2006, 6, (6), 1261-1268.

[25] Oostingh, G.J.; Casals, E.; Italiani, P.; Colognato, R.; Stritzinger, R.; Ponti, J.; Pfaller, T.; Kohl, Y.; Ooms, D.; Favilli, F.; Leppens, H.; Lucchesi, D.; Rossi, F.; Nelissen, I.; Thielecke, H.; Puntes, V.F.; Duschl, A.; Boraschi, D., Problems and challenges in the development and validation of human cell-based assays to determine nanoparticle-induced immunomodulatory effects. Part Fibre Toxicol, 2011, 8, (1), 8.

[26] Auffan, M.; Rose, J.; Bottero, J.Y.; Lowry, G.V.; Jolivet, J.P.; Wiesner, M.R., Towards a definition of inorganic nanoparticles from an environmental, health and safety perspective. Nature Nanotechnology, 2009, 4, (10), 634-641.

[27] Valko, M.; Rhodes, C.J.; Moncol, J.; Izakovic, M.; Mazur, M., Free radicals, metals and antioxidants in oxidative stress-induced cancer. Chem. Biol. Interact., 2006, 160, (1), 1-40.

[28] Xia, T.; Kovochich, M.; Brant, J.; Hotze, M.; Sempf, J.; Oberley, T.; Sioutas, C.; Yeh, J.I.; Wiesner, M.R.; Nel, A.E., Comparison of the Abilities of Ambient and Manufactured Nanoparticles To Induce Cellular Toxicity According to an Oxidative Stress Paradigm. Nano Lett., 2006, 6, (8), 1794-1807.

[29] Kirchner, C.; Liedl, T.; Kudera, S.; Pellegrino, T.; Munoz Javier, A.; Gaub, H.E.; Stolzle, S.; Fertig, N.; Parak, W.J., Cytotoxicity of colloidal CdSe and CdSe/ZnS nanoparticles. Nano Lett., 2005, 5, (2), 331-338.

[30] Blanco, E.; Shen, H.; Ferrari, M., Principles of nanoparticle design for overcoming biological barriers to drug delivery. Nat Biotech, 2015, 33, (9), 941-951.

[31] Dostert, C.; Pétrilli, V.; Van Bruggen, R.; Steele, C.; Mossman, B.T.; Tschopp, J., Innate Immune Activation Through Nalp3 Inflammasome Sensing of Asbestos and Silica. Science, 2008, 320, (5876), 674677. 
[32] Fu, P.P.; Xia, Q.; Hwang, H.-M.; Ray, P.C.; Yu, H., Mechanisms of nanotoxicity: Generation of reactive oxygen species. J. Food Drug Anal., 2014, 22, (1), 64-75.

[33] Manke, A.; Wang, L.; Rojanasakul, Y., Mechanisms of Nanoparticle-Induced Oxidative Stress and Toxicity. BioMed Research International, 2013, 2013, 15.

[34] Jose Ruben, M.; Jose Luis, E.; Alejandra, C.; Katherine, H.; Juan, B.K.; Jose Tapia, R.; Miguel Jose, Y., The bactericidal effect of silver nanoparticles. Nanotechnology, 2005, 16, (10), 2346.

[35] del Pino, P.; Yang, F.; Pelaz, B.; Zhang, Q.; Kantner, K.; Hartmann, R.; Martinez de Baroja, N.; Gallego, M.; Möller, M.; Manshian, B.B.; Soenen, S.J.; Riedel, R.; Hampp, N.; Parak, W.J., Basic Physicochemical Properties of Polyethylene Glycol Coated Gold Nanoparticles that Determine Their Interaction with Cells. Angewandte Chemie International Edition, 2016, 55, (18), 5483-5487.

[36] Pelaz, B.; del Pino, P.; Maffre, P.; Hartmann, R.; Gallego, M.; Rivera-Fernández, S.; de la Fuente, J.M.; Nienhaus, G.U.; Parak, W.J., Surface Functionalization of Nanoparticles with Polyethylene Glycol: Effects on Protein Adsorption and Cellular Uptake. ACS Nano, 2015, 9, (7), 6996-7008.

[37] Lynch, I.; Weiss, C.; Valsami-Jones, E., A strategy for grouping of nanomaterials based on key physico-chemical descriptors as a basis for safer-by-design NMs. Nano Today, 2014, 9, (3), 266-270.

[38] Kuempel, E.D.; Castranova, V.; Geraci, C.L.; Schulte, P.A., Development of risk-based nanomaterial groups for occupational exposure control. Journal of Nanoparticle Research, 2012, 14, (9), 1029.

[39] Oomen, A.G.; Bos, P.M.J.; Fernandes, T.F.; Hund-Rinke, K.; Boraschi, D.; Byrne, H.J.; Aschberger, K.; Gottardo, S.; von der Kammer, F.; Kühnel, D.; Hristozov, D.; Marcomini, A.; Migliore, L.; Scott-Fordsmand, J.; Wick, P.; Landsiedel, R., Concern-driven integrated approaches to nanomaterial testing and assessment - report of the NanoSafety Cluster Working Group 10. Nanotoxicology, 2014, 8, (3), 334-348.

[40] Landsiedel, R.; Ma-Hock, L.; Haussmann, H.J.; van Ravenzwaay, B.; Kayser, M.; Wiench, K., Inhalation studies for the safety assessment of nanomaterials: Status quo and the way forward. Wiley Interdisciplinary Reviews: Nanomedicine and Nanobiotechnology, 2012, 4, (4), 399-413.

[41] Ankley, G.T.; Bennett, R.S.; Erickson, R.J.; Hoff, D.J.; Hornung, M.W.; Johnson, R.D.; Mount, D.R.; Nichols, J.W.; Russom, C.L.; Schmieder, P.K.; Serrrano, J.A.; Tietge, J.E.; Villeneuve, D.L., Adverse outcome pathways: A conceptual framework to support ecotoxicology research and risk assessment. Environ. Toxicol. Chem., 2010, 29, (3), 730-741.

[42] Puzyn, T.; Rasulev, B.; Gajewicz, A.; Hu, X.; Dasari, T.P.; Michalkova, A.; Hwang, H.-M.; Toropov, A.; Leszczynska, D.; Leszczynski, J., Using nano-QSAR to predict the cytotoxicity of metal oxide nanoparticles. Nat Nano, 2011, 6, (3), 175-178.

[43] Burello, E.; Worth, A.P., QSAR modeling of nanomaterials. Wiley Interdisciplinary Reviews: Nanomedicine and Nanobiotechnology, 2011, 3, (3), 298-306.

[44] Richarz, A.-N.; Madden, J.C.; Marchese Robinson, R.L.; Lubiński, Ł.; Mokshina, E.; Urbaszek, P.; Kuz'min, V.E.; Puzyn, T.; Cronin, M.T.D., Development of computational models for the prediction of the toxicity of nanomaterials. Perspectives in Science, 2015, 3, (1-4), 27-29.

[45] Feliu, N.; Docter, D.; Heine, M.; del Pino, P.; Ashraf, S.; Kolosnjaj-Tabi, J.; Macchiarini, P.; Nielsen, P.; Alloyeau, D.; Gazeau, F.; Stauber, R.H.; Parak, W.J., In vivo degeneration and the fate of inorganic nanoparticles. Chem. Soc. Rev., 2016, 45, (9), 2440-2457. 
[46] Lison, D.; Huaux, F., In vitro studies: ups and downs of cellular uptake. Nature nanotechnology, 2011, 6, 332-333.

[47] Hardman, R., A Toxicologic Review of Quantum Dots: Toxicity Depends on Physicochemical and Environmental Factors. Environ. Health Perspect., 2006, 114, (2), 165-172.

[48] Desai, N., Challenges in Development of Nanoparticle-Based Therapeutics. The AAPS Journal, 2012, 14, (2), 282-295.

[49] Bastús, N.G.; Gonzalez, E.; Esteve, J.; Piella, J.; Patarroyo, J.; Merkoçi, F.; Puntes, V., Exploring New Synthetic Strategies for the Production of Advanced Complex Inorganic Nanocrystals. Z. Phys. Chem., 2015, 229, (1-2), 65-83.

[50] Hühn, J.; Carrillo-Carrion, C.; Soliman, M.G.; Pfeiffer, C.; Valdeperez, D.; Masood, A.; Chakraborty, I.; Zhu, L.; Gallego, M.; Yue, Z.; Carril, M.; Feliu, N.; Escudero, A.; Alkilany, A.M.; Pelaz, B.; del Pino, P.; Parak, W.J., Selected Standard Protocols for the Synthesis, Phase Transfer, and Characterization of Inorganic Colloidal Nanoparticles. Chem. Mater., 2017, 29, (1), 399-461.

[51] Zhang, L.; Xia, Y., Scaling up the Production of Colloidal Nanocrystals: Should We Increase or Decrease the Reaction Volume? Adv. Mater., 2014, 26, (16), 2600-2606.

[52] Bastús, N.G.; Casals, E.; Vazquez-Campos, S.; Puntes, V., Reactivity of Engineered Inorganic Nanoparticles and Carbon Nanostructures in Biological Media. Nanotoxicology, 2008, 2, (3), 99-112.

[53] Karlsson, H.L.; Gustafsson, J.; Cronholm, P.; Möller, L., Size-dependent toxicity of metal oxide particles - a comparison between nano-and micrometer size. Toxicology letters, 2009, 188, (2), 112-118.

[54] Jiang, W.; Kim, B.Y.S.; Rutka, J.T.; Chan, W.C.W., Nanoparticle-mediated cellular response is size-dependent. Nature Nanotechnology, 2008, 3, (3), 145-150.

[55] Shang, L.; Nienhaus, K.; Nienhaus, G.U., Engineered nanoparticles interacting with cells: size matters. Journal of Nanobiotechnology, 2014, 12, 5-5.

[56] Schübbe, S.; Schumann, C.; Cavelius, C.; Koch, M.; Müller, T.; Kraegeloh, A., Size-Dependent Localization and Quantitative Evaluation of the Intracellular Migration of Silica Nanoparticles in Caco-2 Cells. Chem. Mater., 2012, 24, (5), 914-923.

[57] Jiang, J.; Oberdörster, G.; Elder, A.; Gelein, R.; Mercer, P.; Biswas, P., Does Nanoparticle Activity Depend upon Size and Crystal Phase? Nanotoxicology, 2008, 2, (1), 33-42.

[58] Jin, C.; Tang, Y.; Yang, F.G.; Li, X.L.; Xu, S.; Fan, X.Y.; Huang, Y.Y.; Yang, Y.J., Cellular toxicity of $\mathrm{TiO} 2$ nanoparticles in anatase and rutile crystal phase. Biol Trace Elem Res, 2011, 141, (1-3), 315.

[59] Braydich-Stolle, L.K.; Schaeublin, N.M.; Murdock, R.C.; Jiang, J.; Biswas, P.; Schlager, J.J.; Hussain, S.M., Crystal structure mediates mode of cell death in $\mathrm{TiO} 2$ nanotoxicity. Journal of Nanoparticle Research, 2009, 11, (6), 1361-1374.

[60] Jiang, J.; Oberdörster, G.; Biswas, P., Characterization of size, surface charge, and agglomeration state of nanoparticle dispersions for toxicological studies. Journal of Nanoparticle Research, 2009, 11, (1), 77-89. 
[61] Abdelmonem, A.M.; Pelaz, B.; Kantner, K.; Bigall, N.C.; del Pino, P.; Parak, W.J., Charge and agglomeration dependent in vitro uptake and cytotoxicity of zinc oxide nanoparticles. J. Inorg. Biochem., 2015, 153, 334-338.

[62] Verma, A.; Stellacci, F., Effect of surface properties on nanoparticle-cell interactions. Small, 2010, $6,(1), 12-21$.

[63] Fröhlich, E., The role of surface charge in cellular uptake and cytotoxicity of medical nanoparticles. International Journal of Nanomedicine, 2012, 7, 5577-5591.

[64] Bastús, N.G.; Casals, E.; Ojea, I.; Varon, M.; Puntes, V. In The Delivery of Nanoparticles. Hashim, A.A., Ed.; InTech, 2012.

[65] Mudunkotuwa, I.A.; Grassian, V.H., The devil is in the details (or the surface): impact of surface structure and surface energetics on understanding the behavior of nanomaterials in the environment. $J$. Environ. Monit., 2011, 13, (5), 1135-1144.

[66] Liu, J.; Hurt, R.H., Ion Release Kinetics and Particle Persistence in Aqueous Nano-Silver Colloids. Environmental Science \& Technology, 2010, 44, (6), 2169-2175.

[67] Reidy, B.; Haase, A.; Luch, A.; Dawson, K.; Lynch, I., Mechanisms of Silver Nanoparticle Release, Transformation and Toxicity: A Critical Review of Current Knowledge and Recommendations for Future Studies and Applications. Materials, 2013, 6, (6), 2295.

[68] Stebounova, L.V.; Guio, E.; Grassian, V.H., Silver nanoparticles in simulated biological media: a study of aggregation, sedimentation, and dissolution. Journal of Nanoparticle Research, 2011, 13, (1), 233244.

[69] Wang, X.; Ji, Z.; Chang, C.H.; Zhang, H.; Wang, M.; Liao, Y.-P.; Lin, S.; Meng, H.; Li, R.; Sun, B.; Winkle, L.V.; Pinkerton, K.E.; Zink, J.I.; Xia, T.; Nel, A.E., Use of Coated Silver Nanoparticles to Understand the Relationship of Particle Dissolution and Bioavailability to Cell and Lung Toxicological Potential. Small, 2014, 10, (2), 385-398.

[70] Nel, A.E.; Madler, L.; Velegol, D.; Xia, T.; Hoek, E.M.V.; Somasundaran, P.; Klaessig, F.; Castranova, V.; Thompson, M., Understanding biophysicochemical interactions at the nano-bio interface. Nat Mater, 2009, 8, (7), 543-557.

[71] Maynard, A.D.; Warheit, D.B.; Philbert, M.A., The New Toxicology of Sophisticated Materials: Nanotoxicology and Beyond. Toxicol. Sci., 2011, 120, (suppl 1), S109-S129.

[72] Axson, J.L.; Stark, D.I.; Bondy, A.L.; Capracotta, S.S.; Maynard, A.D.; Philbert, M.A.; Bergin, I.L.; Ault, A.P., Rapid Kinetics of Size and pH-Dependent Dissolution and Aggregation of Silver Nanoparticles in Simulated Gastric Fluid. J. Phys. Chem. C, 2015, 119, (35), 20632-20641.

[73] Elzey, S.; Grassian, V.H., Agglomeration, isolation and dissolution of commercially manufactured silver nanoparticles in aqueous environments. Journal of Nanoparticle Research, 2010, 12, (5), 1945-1958.

[74] Pelaz, B.; Charron, G.; Pfeiffer, C.; Zhao, Y.; de la Fuente, J.M.; Liang, X.-J.; Parak, W.J.; del Pino, P., Interfacing Engineered Nanoparticles with Biological Systems: Anticipating Adverse Nano-Bio Interactions. Small, 2013, 9, (9-10), 1573-1584.

[75] Oostingh, G.J.; Casals, E.; Italiani, P.; Colognato, R.; Stritzinger, R.; Ponti, J.; Pfaller, T.; Kohl, Y.; Ooms, D.; Favilli, F.; Leppens, H.; Lucchesi, D.; Rossi, F.; Nelissen, I.; Thielecke, H.; Puntes, V.F.; Duschl, A.; Boraschi, D., Problems and challenges in the development and validation of human cell-based 
assays to determine nanoparticle-induced immunomodulatory effects. Particle and Fibre Toxicology, 2011, 8 .

[76] Sager, T.M.; Porter, D.W.; Robinson, V.A.; Lindsley, W.G.; Schwegler-Berry, D.E.; Castranova, V., Improved method to disperse nanoparticles for in vitro and in vivo investigation of toxicity. Nanotoxicology, 2007, 1, (2), 118-129.

[77] Casals, E.; Pfaller, T.; Duschl, A.; Oostingh, G.J.; Puntes, V., Time evolution of the nanoparticle protein corona. ACS Nano, 2010, 4, (7), 3623-3632.

[78] Casals, E.; Pfaller, T.; Duschl, A.; Oostingh, G.J.; Puntes, V.F., Hardening of the nanoparticleprotein corona in metal $(\mathrm{Au}, \mathrm{Ag})$ and oxide (Fe3O4, $\mathrm{CoO}$, and $\mathrm{CeO} 2)$ nanoparticles. Small, 2011, 7, (24), 3479-3486.

[79] Piella, J.; Bastús, N.G.; Puntes, V., Size-dependent Protein-Nanoparticle Interactions in Citratestabilized Gold Nanoparticles: The Emergence of the Protein Corona. Bioconjugate Chemistry, 2016, 28, (1), 88-97.

[80] Lo Giudice, M.C.; Herda, L.M.; Polo, E.; Dawson, K.A., In situ characterization of nanoparticle biomolecular interactions in complex biological media by flow cytometry. Nature Communications, 2016, 7,13475 .

[81] Saptarshi, S.R.; Duschl, A.; Lopata, A.L., Interaction of nanoparticles with proteins: relation to bio-reactivity of the nanoparticle. Journal of Nanobiotechnology, 2013, 11, 26-26.

[82] Ding, F.; Radic, S.; Chen, R.; Chen, P.; Geitner, N.K.; Brown, J.M.; Ke, P.C., Direct observation of a single nanoparticle-ubiquitin corona formation. Nanoscale, 2013, 5, (19), 9162-9169.

[83] Podila, R.; Chen, R.; Ke, P.C.; Brown, J.M.; Rao, A.M., Effects of surface functional groups on the formation of nanoparticle-protein corona. Applied Physics Letters, 2012, 101, (26), 263701.

[84] Cedervall, T.; Lynch, I.; Lindman, S.; Berggard, T.; Thulin, E.; Nilsson, H.; Dawson, K.A.; Linse, S., Understanding the nanoparticle-protein corona using methods to quantify exchange rates and affinities of proteins for nanoparticles. Proc. Natl. Acad. Sci. U. S. A., 2007, 104, (7), 2050-2055.

[85] Herda, L.M.; Hristov, D.R.; Lo Giudice, M.C.; Polo, E.; Dawson, K.A., Mapping of Molecular Structure of the Nanoscale Surface in Bionanoparticles. J. Am. Chem. Soc., 2017, 139, (1), 111-114.

[86] Kelly, P.M.; Åberg, C.; Polo, E.; O'Connell, A.; Cookman, J.; Fallon, J.; KrpetićŽeljka; Dawson, K.A., Mapping protein binding sites on the biomolecular corona of nanoparticles. Nat Nano, 2015, 10, (5), 472-479.

[87] Casals, E.; Puntes, V.F., Inorganic nanoparticle biomolecular corona: formation, evolution and biological impact. Nanomedicine (Lond), 2012, 7, (12), 1917-1930.

[88] Lynch, I.; Cedervall, T.; Lundqvist, M.; Cabaleiro-Lago, C.; Linse, S.; Dawson, K.A., The nanoparticle-protein complex as a biological entity; a complex fluids and surface science challenge for the 21st century. Advances in Colloid and Interface Science, 2007, 134-135, 167-174.

[89] Monopoli, M.P.; Walczyk, D.; Campbell, A.; Elia, G.; Lynch, I.; Baldelli Bombelli, F.; Dawson, K.A., Physical-Chemical Aspects of Protein Corona: Relevance to in Vitro and in Vivo Biological Impacts of Nanoparticles. J. Am. Chem. Soc., 2011, 133, (8), 2525-2534. 
[90] Walczyk, D.; Bombelli, F.B.; Monopoli, M.P.; Lynch, I.; Dawson, K.A., What the Cell "Sees" in Bionanoscience. J. Am. Chem. Soc., 2010, 132, (16), 5761-5768.

[91] Lynch, I.; Dawson, K.A., Protein-nanoparticle interactions. Nano Today, 2008, 3, (1-2), 40-47.

[92] Oberdörster, G.; Maynard, A.; Donaldson, K.; Castranova, V.; Fitzpatrick, J.; Ausman, K.; Carter, J.; Karn, B.; Kreyling, W.; Lai, D.; Olin, S.; Monteiro-Riviere, N.; Warheit, D.; Yang, H., Principles for characterizing the potential human health effects from exposure to nanomaterials: elements of a screening strategy. Particle and Fibre Toxicology, 2005, 2, (1), 8.

[93] Warheit, D.B., How meaningful are the results of nanotoxicity studies in the absence of adequate material characterization? Toxicol. Sci., 2008, 101, (2), 183-185.

[94] Cedervall, T.; Lynch, I.; Foy, M.; Berggad, T.; Donnelly, S.C.; Cagney, G.; Linse, S.; Dawson, K.A., Detailed identification of plasma proteins adsorbed on copolymer nanoparticles. Angewandte Chemie-International Edition, 2007, 46, (30), 5754-5756.

[95] Lu, D.; Liu, Q.; Zhang, T.; Cai, Y.; Yin, Y.; Jiang, G., Stable silver isotope fractionation in the natural transformation process of silver nanoparticles. Nat Nano, 2016, 11, (8), 682-686.

[96] Soto-Alvaredo, J.; Montes-Bayón, M.; Bettmer, J., Speciation of Silver Nanoparticles and Silver(I) by Reversed-Phase Liquid Chromatography Coupled to ICPMS. Anal. Chem., 2013, 85, (3), 1316-1321.

[97] Zhang, H.; Ji, Z.; Xia, T.; Meng, H.; Low-Kam, C.; Liu, R.; Pokhrel, S.; Lin, S.; Wang, X.; Liao, Y.-P.; Wang, M.; Li, L.; Rallo, R.; Damoiseaux, R.; Telesca, D.; Mädler, L.; Cohen, Y.; Zink, J.I.; Nel, A.E., Use of Metal Oxide Nanoparticle Band Gap to Develop a Predictive Paradigm for Oxidative Stress and Acute Pulmonary Inflammation. ACS nano, 2012, 6, (5), 4349-4368.

[98] Piella, J.; Bastús, N.G.; Puntes, V., Modeling the Optical Responses of Noble Metal Nanoparticles Subjected to Physicochemical Transformations in Physiological Environments: Aggregation, Dissolution and Oxidation. Z. Phys. Chem., 2017, 231, (1).

[99] Casals, E.; Vázquez-Campos, S.; Bastús, N.G.; Puntes, V., Distribution and potential toxicity of engineered inorganic nanoparticles and carbon nanostructures in biological systems. $\operatorname{Tr} A C \operatorname{Tr} e n d s$ in Analytical Chemistry, 2008, 27, (8), 672-683.

[100] Bahadar, H.; Maqbool, F.; Niaz, K.; Abdollahi, M., Toxicity of Nanoparticles and an Overview of Current Experimental Models. Iranian Biomedical Journal, 2016, 20, (1), 1-11.

[101] Verma, A.; Stellacci, F., Effect of Surface Properties on Nanoparticle-Cell Interactions. Small, 2010, 6, (1), 12-21.

[102] Tiede, K.; Hassellöv, M.; Breitbarth, E.; Chaudhry, Q.; Boxall, A.B.A., Considerations for environmental fate and ecotoxicity testing to support environmental risk assessments for engineered nanoparticles. J. Chromatogr. A, 2009, 1216, (3), 503-509.

[103] Verma, A.; Uzun, O.; Hu, Y.; Hu, Y.; Han, H.-S.; Watson, N.; Chen, S.; Irvine, D.J.; Stellacci, F., Surface-structure-regulated cell-membrane penetration by monolayer-protected nanoparticles. Nat Mater, 2008, 7, (7), 588-595.

[104] Chen, K.L.; Bothun, G.D., Nanoparticles Meet Cell Membranes: Probing Nonspecific Interactions using Model Membranes. Environmental Science \& Technology, 2014, 48, (2), 873-880. 
[105] Rascol, E.; Devoisselle, J.-M.; Chopineau, J., The relevance of membrane models to understand nanoparticles-cell membrane interactions. Nanoscale, 2016, 8, (9), 4780-4798.

[106] Moncelli, M.R.; Becucci, L.; Nelson, A.; Guidelli, R., Electrochemical modeling of electron and proton transfer to ubiquinone-10 in a self-assembled phospholipid monolayer. Biophys. J., 1996, 70, (6), 2716-2726.

[107] Tatur, S.; Maccarini, M.; Barker, R.; Nelson, A.; Fragneto, G., Effect of Functionalized Gold Nanoparticles on Floating Lipid Bilayers. Langmuir, 2013, 29, (22), 6606-6614.

[108] Fleischer, C.C.; Payne, C.K., Nanoparticle-Cell Interactions: Molecular Structure of the Protein Corona and Cellular Outcomes. Acc. Chem. Res., 2014, 47, (8), 2651-2659.

[109] Murugan, K.; Choonara, Y.E.; Kumar, P.; Bijukumar, D.; du Toit, L.C.; Pillay, V., Parameters and characteristics governing cellular internalization and trans-barrier trafficking of nanostructures. International Journal of Nanomedicine, 2015, 10, 2191-2206.

[110] Jiang, W.; Kim, B.; Rutka, J.; Chan, W., Nanoparticle-mediated cellular response is sizedependent. Nature Nanotechnology, 2008, 3, (3), 145 - 150.

[111] Duan, X.; Li, Y., Physicochemical characteristics of nanoparticles affect circulation, biodistribution, cellular internalization, and trafficking. Small, 2013, 9, (9-10), 1521-1532.

[112] Manke, A.; Wang, L.; Rojanasakul, Y., Mechanisms of nanoparticle-induced oxidative stress and toxicity. BioMed research international, 2013, 2013.

[113] Hauck, T.S.; Ghazani, A.A.; Chan, W.C., Assessing the effect of surface chemistry on gold nanorod uptake, toxicity, and gene expression in mammalian cells. Small, 2008, 4, (1), 153-159.

[114] Lei, R.; Wu, C.; Yang, B.; Ma, H.; Shi, C.; Wang, Q.; Wang, Q.; Yuan, Y.; Liao, M., Integrated metabolomic analysis of the nano-sized copper particle-induced hepatotoxicity and nephrotoxicity in rats: A rapid in vivo screening method for nanotoxicity. Toxicol. Appl. Pharmacol., 2008, 232, (2), 292-301.

[115] Pearce, E.L.; Pearce, E.J., Metabolic Pathways In Immune Cell Activation And Quiescence. Immunity, 2013, 38, (4), 633-643.

[116] Vevers, W.F.; Jha, A.N., Genotoxic and cytotoxic potential of titanium dioxide (TiO2) nanoparticles on fish cells in vitro. Ecotoxicology, 2008, 17, (5), 410-420.

[117] Myllynen, P., Nanotoxicology: Damaging DNA from a distance. Nat Nano, 2009, 4, (12), 795796.

[118] Watson, C.; Ge, J.; Cohen, J.; Pyrgiotakis, G.; Engelward, B.P.; Demokritou, P., High-Throughput Screening Platform for Engineered Nanoparticle-Mediated Genotoxicity Using CometChip Technology. ACS Nano, 2014, 8, (3), 2118-2133.

[119] Vallhov, H.; Qin, J.; Johansson, S.M.; Ahlborg, N.; Muhammed, M.A.; Scheynius, A.; Gabrielsson, S., The importance of an endotoxin-free environment during the production of nanoparticles used in medical applications. Nano Lett., 2006, 6, (8), 1682-1686.

[120] Li, M.; Al-Jamal, K.T.; Kostarelos, K.; Reineke, J., Physiologically Based Pharmacokinetic Modeling of Nanoparticles. ACS Nano, 2010, 4, (11), 6303-6317. 
[121] Zhang, Y.; Bai, Y.; Jia, J.; Gao, N.; Li, Y.; Zhang, R.; Jiang, G.; Yan, B., Perturbation of physiological systems by nanoparticles. Chem. Soc. Rev., 2014, 43, (10), 3762-3809.

[122] Hall, J.B.; Dobrovolskaia, M.A.; Patri, A.K.; McNeil, S.E., Characterization of nanoparticles for therapeutics. Nanomedicine (Lond), 2007, 2, (6), 789-803.

[123] Bose, T.; Latawiec, D.; Mondal, P.P.; Mandal, S., Overview of nano-drugs characteristics for clinical application: the journey from the entry to the exit point. Journal of Nanoparticle Research, 2014, $16,(8), 1-25$.

[124] Petros, R.A.; DeSimone, J.M., Strategies in the design of nanoparticles for therapeutic applications. Nature reviews. Drug discovery, 2010, 9, (8), 615-627.

[125] Zhu, M.-T.; Feng, W.-Y.; Wang, Y.; Wang, B.; Wang, M.; Ouyang, H.; Zhao, Y.-L.; Chai, Z.-F., Particokinetics and Extrapulmonary Translocation of Intratracheally Instilled Ferric Oxide Nanoparticles in Rats and the Potential Health Risk Assessment. Toxicol. Sci., 2008, 107, (2), 342-351.

[126] Elder, A.; Gelein, R.; Silva, V.; Feikert, T.; Opanashuk, L.; Carter, J.; Potter, R.; Maynard, A.; Ito, Y.; Finkelstein, J.; Oberdörster, G., Translocation of Inhaled Ultrafine Manganese Oxide Particles to the Central Nervous System. Environ. Health Perspect., 2006, 114, (8), 1172-1178.

[127] Wang, J.; Liu, Y.; Jiao, F.; Lao, F.; Li, W.; Gu, Y.; Li, Y.; Ge, C.; Zhou, G.; Li, B.; Zhao, Y.; Chai, Z.; Chen, C., Time-dependent translocation and potential impairment on central nervous system by intranasally instilled TiO2 nanoparticles. Toxicology, 2008, 254, (1-2), 82-90.

[128] Bai, Y.; Zhang, Y.; Zhang, J.; Mu, Q.; Zhang, W.; Butch, E.R.; Snyder, S.E.; Yan, B., Repeated administrations of carbon nanotubes in male mice cause reversible testis damage without affecting fertility. Nat Nano, 2010, 5, (9), 683-689.

[129] Ma, X.; Wu, Y.; Jin, S.; Tian, Y.; Zhang, X.; Zhao, Y.; Yu, L.; Liang, X.-J., Gold Nanoparticles Induce Autophagosome Accumulation through Size-Dependent Nanoparticle Uptake and Lysosome Impairment. ACS Nano, 2011, 5, (11), 8629-8639.

[130] Jokerst, J.V.; Lobovkina, T.; Zare, R.N.; Gambhir, S.S., Nanoparticle PEGylation for imaging and therapy. Nanomedicine (London, England), 2011, 6, (4), 715-728.

[131] Zhu, M.; Nie, G.; Meng, H.; Xia, T.; Nel, A.; Zhao, Y., Physicochemical Properties Determine Nanomaterial Cellular Uptake, Transport, and Fate. Acc. Chem. Res., 2013, 46, (3), 622-631.

[132] Raya, A.; Rodriguez-Piza, I.; Navarro, S.; Richaud-Patin, Y.; Guenechea, G.; Sanchez-Danes, A.; Consiglio, A.; Bueren, J.; Izpisua Belmonte, J.C., A protocol describing the genetic correction of somatic human cells and subsequent generation of iPS cells. Nat. Protoc., 2010, 5, (4), 647-660.

[133] Kunzmann, A.; Andersson, B.; Thurnherr, T.; Krug, H.; Scheynius, A.; Fadeel, B., Toxicology of engineered nanomaterials: Focus on biocompatibility, biodistribution and biodegradation. Biochimica et Biophysica Acta (BBA) - General Subjects, 2011, 1810, (3), 361-373.

[134] King-Heiden, T.C.; Wiecinski, P.N.; Mangham, A.N.; Metz, K.M.; Nesbit, D.; Pedersen, J.A.; Hamers, R.J.; Heideman, W.; Peterson, R.E., Quantum Dot Nanotoxicity Assessment Using the Zebrafish Embryo. Environmental science \& technology, 2009, 43, (5), 1605-1611.

[135] Evensen, L.; Johansen, P.L.; Koster, G.; Zhu, K.; Herfindal, L.; Speth, M.; Fenaroli, F.; Hildahl, J.; Bagherifam, S.; Tulotta, C.; Prasmickaite, L.; Maelandsmo, G.M.; Snaar-Jagalska, E.; Griffiths, G., 
Zebrafish as a model system for characterization of nanoparticles against cancer. Nanoscale, 2016, 8, (2), 862-877.

[136] Asharani, P.; Wu, Y.L.; Gong, Z.; Valiyaveettil, S., Toxicity of silver nanoparticles in zebrafish models. Nanotechnology, 2008, 19, (25), 255102.

[137] Esch, E.W.; Bahinski, A.; Huh, D., Organs-on-chips at the frontiers of drug discovery. Nature reviews. Drug discovery, 2015, 14, (4), 248-260.

[138] Corsi, I.; Cherr, G.N.; Lenihan, H.S.; Labille, J.; Hassellov, M.; Canesi, L.; Dondero, F.; Frenzilli, G.; Hristozov, D.; Puntes, V.; Della Torre, C.; Pinsino, A.; Libralato, G.; Marcomini, A.; Sabbioni, E.; Matranga, V., Common Strategies and Technologies for the Ecosafety Assessment and Design of Nanomaterials Entering the Marine Environment. ACS Nano, 2014, 8, (10), 9694-9709.

[139] Colvin, V.L., The potential environmental impact of engineered nanomaterials. Nature Biotechnology, 2003, 21, (10), 1166-1170.

[140] Mueller, N.C.; Nowack, B., Exposure Modeling of Engineered Nanoparticles in the Environment. Environmental Science \& Technology, 2008, 42, (12), 4447-4453.

[141] Yang, Y.; Zhang, C.; Hu, Z., Impact of metallic and metal oxide nanoparticles on wastewater treatment and anaerobic digestion. Environmental Science: Processes \& Impacts, 2013, 15, (1), 39-48.

[142] Kaegi, R.; Voegelin, A.; Sinnet, B.; Zuleeg, S.; Hagendorfer, H.; Burkhardt, M.; Siegrist, H., Behavior of metallic silver nanoparticles in a pilot wastewater treatment plant. Environmental science \& technology, 2011, 45, (9), 3902-3908.

[143] Kiser, M.; Westerhoff, P.; Benn, T.; Wang, Y.; Perez-Rivera, J.; Hristovski, K., Titanium nanomaterial removal and release from wastewater treatment plants. Environmental science \& technology, 2009, 43, (17), 6757-6763.

[144] Klaine, S.J.; Alvarez, P.J.; Batley, G.E.; Fernandes, T.F.; Handy, R.D.; Lyon, D.Y.; Mahendra, S.; McLaughlin, M.J.; Lead, J.R., Nanomaterials in the environment: behavior, fate, bioavailability, and effects. Environ. Toxicol. Chem., 2008, 27, (9), 1825-1851.

[145] Batley, G.E.; Kirby, J.K.; McLaughlin, M.J., Fate and risks of nanomaterials in aquatic and terrestrial environments. Acc. Chem. Res., 2012, 46, (3), 854-862.

[146] Baun, A.; Hartmann, N.B.; Grieger, K.; Kusk, K.O., Ecotoxicity of engineered nanoparticles to aquatic invertebrates: a brief review and recommendations for future toxicity testing. Ecotoxicology, 2008, 17, (5), 387-395. 